\title{
Low Shear Granulation
}

National Cancer Institute

\section{Source}

National Cancer Institute. Low Shear Granulation. NCI Thesaurus. Code C113012.

The use of a series of integ rated steps whereby a dry powder is conditioned by wetting or is melted to form a plasticized mass that with the aid of low shear forces, yields particles possessing characteristic dimensions and density. 